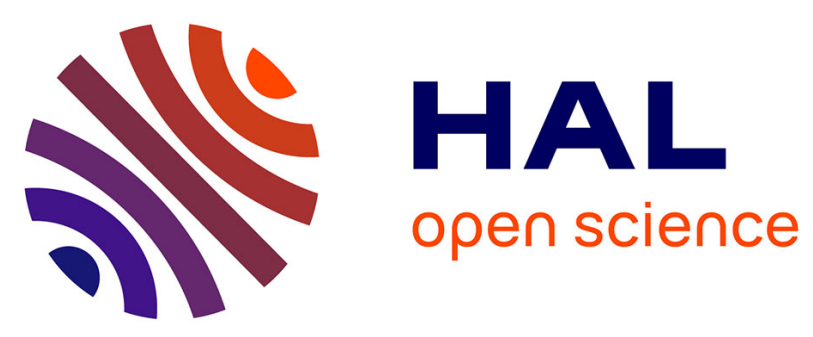

\title{
Intercomparison of reactive transport models applied to UO2 oxidative dissolution and uranium migration
}

\author{
Laurent de Windt, André Burnol, Philippe Montarnal, Jan van Der Lee
}

\section{To cite this version:}

Laurent de Windt, André Burnol, Philippe Montarnal, Jan van Der Lee. Intercomparison of reactive transport models applied to UO2 oxidative dissolution and uranium migration. Journal of Contaminant Hydrology, 2003, 8th Internation Conference on Chemistry and Migration Behaviour of Actinides and Fission Products in the Geosphere - Migration 01, 61 (1-4), pp.303-312. 10.1016/S01697722(02)00127-4 . hal-00596553

HAL Id: hal-00596553

https: / hal-mines-paristech.archives-ouvertes.fr/hal-00596553

Submitted on 3 Nov 2016

HAL is a multi-disciplinary open access archive for the deposit and dissemination of scientific research documents, whether they are published or not. The documents may come from teaching and research institutions in France or abroad, or from public or private research centers.
L'archive ouverte pluridisciplinaire HAL, est destinée au dépôt et à la diffusion de documents scientifiques de niveau recherche, publiés ou non, émanant des établissements d'enseignement et de recherche français ou étrangers, des laboratoires publics ou privés. 


\title{
Intercomparison of reactive transport models applied to $\mathrm{UO}_{2}$ oxidative dissolution and uranium migration.
}

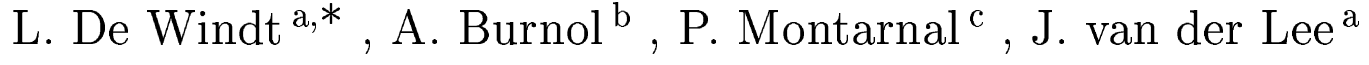 \\ ${ }^{\mathrm{a}}$ Ecole des Mines de Paris, CIG, 77300 Fontainebleau, France. \\ ${ }^{\mathrm{b}}$ Electricité de France, DRED/LNHE, 78401 Chatou, France. \\ ${ }^{\mathrm{c} C o m m i s s a r i a t ~ a ̀ ~ l ' E n e r g i e ~ A t o m i q u e, ~ D E N / D M 2 S, ~} 91191$ Gif-sur-Yvette, France.
}

\begin{abstract}
Oxidative dissolution of uranium dioxide and the subsequent migration of uranium in a subsurface environment and an underground waste disposal have been simulated with reactive transport models. In these systems, hydrogeological and chemical processes are closely entangled and their interdependency has been analyzed in detail, notably with respect to redox reactions, kinetics of mineralogical evolution and hydrodynamic migration of species of interest.

Different codes, where among CASTEM, CHEMTRAP and HYTEC, have been used as an intercomparison and verification exercise. Although the agreement between codes is satisfactory, it is shown that the discretization method of the transport equation (i.e. finite elements (FE) versus mixed-hybrid FE and finite differences) and the sequential coupling scheme may lead to systematic discrepancies.
\end{abstract}

Key words: reactive transport, uranium dioxide, oxidative dissolution, uranium migration, intercomparison.

Revised manuscript for J. Cont. Hydr.

8 January 2002 


\section{Introduction}

Oxidative dissolution of uraninite and spent fuel, and the subsequent migration of uranium, are relevant processes for accidental radioactive pollutions and the disposal of spent nuclear fuel. A resembling leaching behaviour of uraninite and spent fuel has been observed under oxic or mildly reducing conditions (Bruno et al., 1995; Cachoir et al., 1996; Wronkiewicz et al., 1996; Serrano et al., 1998). Uranium dioxide, $\mathrm{UO}_{2}$, is readily oxidized to $\mathrm{UO}_{2+x}$ $(\mathrm{x} \leq 0.67)$ and then to uranyl-oxide hydrates such as becquerelite and schoepite. This transient process is kinetically favored but thermodynamically unstable and, depending on the chemical composition of leachates, followed by the formation of uranyl silicates (soddyite) and/or alkali-alkaline earth silicates (bolwoodite, uranophane) as end products. The actual mobility of uranium is the result of competition between aqueous ligands (carbonates, hydroxyls, phosphates, sulfates, organics), precipitation of secondary uranium minerals and sorption on solid phases (clays, ferric hydroxides, humic substances). In soils, uranium migration is usually restricted to a few tens of centimeters but can be enhanced by colloidal transport and carbonate complexation (van der Lee et al., 1992; Elless and Lee, 1998).

The hydrogeological and chemical reactions of deep-underground or subsurface systems are closely entangled, and transport models coupled with chemistry are increasingly used to simulate the dissolution and migration processes (van der Lee and De Windt, 2001). The main objective of this paper is to present an intercomparison study using different reactive transport codes, where among CASTEM (CEA, 1999), CHEMTRAP (Lucille et al., 2000),

\footnotetext{
* Corresponding author. Email: dewindt@cig.ensmp.fr
} 
HYTEC (van der Lee and De Windt, 2001) and PHREEQC (Parkhurst and Appelo, 1999). To a lesser extent, the hydro-geochemical behaviour of such systems characterized by strong redox fronts and kinetics is also discussed. The first case-study concerns the leaching of an uranium enriched zone by rain water infiltration, and the second the spent fuel degradation in a waste storage disposal under oxidizing conditions.

\section{Reactive transport modeling}

CASTEM, CHEMTRAP and HYTEC combine chemical reactions with hydrogeological processes such as groundwater flow, advective transport with dispersion, diffusion, and for HYTEC, colloidal transport. Chemical processes include, among others, aqueous speciation and redox reactions, interface reactions (surface complexation, ion exchange), and dissolution/precipitation of solids (colloids, minerals). The models make use of thermodynamic databases, hence several hundreds of simultaneously reacting species can be considered. As the codes become increasingly complex, a comprehensive verification process is essential. Comparing numerical results with analytical solutions verifies that the numerical algorithms correctly reflect the mathematical concepts and provides insight into the inherent approximations. The set of analytical solutions, however, is restricted for reactive transport codes. Only the benchmarking between peer codes allows to verify and test the performances of the global procedures (numerical behaviour, input and database management) for more complex applications.

In CASTEM, discretization of the transport equation is based on mixed-hybrid finite elements, MHFE, with a constant concentration in the center of each 
element (Chavant and Roberts, 1991). CHEMTRAP and HYTEC use a finite elements (FE) approach with concentrations defined at the nodes and a linear interpolation between adjacent nodes. Both approaches are well suited for irregular regions and to locate nodes where improved accuracy is needed. FE ill-defines the initial mass of minerals and geometrical boundaries of geochemical zones (defined by a certain number of elements) due to the interpolation procedure between adjacent nodes. Finite differences or the mixed-hybrid FE approaches are more precise with respect to this point.

Each model couples geochemistry with transport according to the sequential iterative approach : chemistry and transport are solved one after the other within a single time step (Yeh and Tripathi, 1989; van der Lee and De Windt, 2001). Since the two sets of equations are interdependent, iterations are required to increase the accuracy to an acceptable level.

The three models use the assumption of local thermodynamic equilibrium (mass balance) and an improved Newton-Raphson procedure to solve the algebraic set of equations. In addition, CHEMTRAP and HYTEC, which share the same chemical engine CHESS (van der Lee, 1998), provide a mixed kinetic/equilibrium approach with respect to dissolution and precipitation:

$$
\frac{\mathrm{d} S}{\mathrm{~d} t}=A_{\mathrm{v}} k \prod_{i}\left[C_{i}\right]^{a_{i}}\left(\frac{Q}{K}-1\right)
$$

where $A_{v}$ is the surface in contact with the solution $\left(\mathrm{m}^{2} / \mathrm{l}\right), \mathrm{k}$ is the rate constant $\left(\mathrm{mol} / \mathrm{m}^{2} / \mathrm{s}\right)$, and $\mathrm{Q} / \mathrm{K}$ is the ratio between the saturation state of the solid and its equilibrium constant. The term $\prod_{i}\left[C_{i}\right]^{a_{i}}$ is solution dependent with $\left[C_{i}\right]$ being the activity of species (catalysis if $a_{i}$ is positive or inhibition otherwise). Since CASTEM does not include kinetics and CHESS is common to both CHEMTRAP and HYTEC, we completed the set of mod- 
els with PHREEQC (Parkhurst and Appelo, 1999) for the second test-case. This code uses an explicit finite difference algorithm for calculation of $1 \mathrm{D}$ advective-dispersive transport, a mixed kinetic-equilibrium approach and an non iterative sequential coupling scheme.

As proposed in the study of CRWMS-MO (1998), the EQ3/6 dataset of Wolery (1992) was selected and enriched with experimental data for uranyl silicates (Nguyen et al., 1992). The rate constant for the uranyl minerals was derived according to Eq. 1 from experimental results at room temperature (Bruno et al., 1995; Pérez et al., 1997). Although probably relevant, no temperature correction was attempted here. The oxidative dissolution rate of spent fuel was derived from the study of Gray et al. (1992). The data used for the uranium minerals are reported in Table 1. The intrinsic constants of Gabriel et al. (1998) were used to model surface complexation of $\mathrm{UO}_{2}{ }^{2+}$ and $\mathrm{UO}_{2} \mathrm{OH}^{+}$on goethite (specific surface $=60 \mathrm{~m}^{2} / \mathrm{g}$ ) and hydrous ferric oxides (specific surface $\left.=100 \mathrm{~m}^{2} / \mathrm{g}\right)$. The densities of low and high affinity sites were respectively of 3.75 and $0.095 \mu \mathrm{mol} / \mathrm{m}^{2}$.

\section{Subsurface migration of uranium}

The configuration of the first benchmark is shown by Figure 1. Rain water infiltrates in a subsurface aquifer and leaches a zone enriched in uraninite. Rainwater is in equilibrium with the atmosphere (fugacity $\mathrm{O}_{2}=0.2$, fugacity

$\mathrm{CO}_{2}=310^{-4}$ ). For reasons of simplicity, the unsaturated zone was neglected and dissolved oxygen does not react with any redox species before reaching $\mathrm{UO}_{2}$. Calcite and quartz are the main minerals of the aquifer, and goethite is present at a lower content $(2.5 \%)$. The aquifer has a relatively high $\mathrm{pH}$ 
(9.0-9.5) and low carbonate contents $\left(\sim 210^{-4} \mathrm{~mol} / \mathrm{l}\right)$. The enriched zone of the aquifer has an average weight content in $\mathrm{UO}_{2}$ of $5 \%$. The percolation rate was set to $2.5 \mathrm{~m} / \mathrm{y}$ for a porosity of $40 \%$. The longitudinal and transverse dispersivities were respectively $1 \mathrm{~m}$ and $1.5 \mathrm{~m}$. A $1 \mathrm{D}$ grid (32 nodes) along the symmetrical axis and a $2 \mathrm{D}$ grid (19 x 32 nodes) were used with Dirichlet conditions at the upper parts. Temperature was fixed to $25{ }^{\circ} \mathrm{C}$.

Figure 2A shows the 2D concentration profiles of dissolved oxygen, $\mathrm{O}_{2}(\mathrm{aq})$, after $100 \mathrm{y}$ as an indicator of redox conditions. $\mathrm{UO}_{2}$ acts as a reducing buffer and the oxidative dissolution of $\mathrm{UO}_{2}$, which is assumed to be in equilibrium in this case, depletes the oxygen content of the groundwater. The dissolved uranium concentration, $\mathrm{U}(\mathrm{aq})$, depends on precipitation of secondary uranium minerals, sorption on the solid phase, dispersion and dilution. Under all circumstances, $\mathrm{UO}_{2}(\mathrm{OH})_{3}{ }^{-}$remains the predominant species in solution. Figure $2 \mathrm{~B}$ illustrates that $\mathrm{U}(\mathrm{aq})$ is controlled by kinetic precipitation of schoepite which replaces, in situ, the uraninite when assuming equilibrium conditions. Under kinetic control $\left(\mathrm{A}_{\mathrm{v}}=1 \mathrm{~m}^{2} / 1\right.$ arbitrarily $)$, schoepite precipitation occurs more downstream.

At equilibrium, uranophane is the most stable mineral and the uranium solubility is reduced by 4 orders of magnitude (Fig. 2C). Downstream migration is slowed down due to sorption on goethite surfaces : this kind of retention is likely to occur in most subsurface systems. Colloidal transport, however, may act like a vehicle for uranium and for heavy or toxic metals in general, which tend to strongly sorb on these particles. Modeling of uranium migration including the colloidal effect is possible with HYTEC and the results are illustrated by Figure 2D. As $50 \mathrm{mg} / \mathrm{l}$ of hydrous ferric oxides (HFO) colloids migrate downwards from the upper right corner, the mobility of uranium is 
moderately enhanced. Note that colloidal transport is significant only when uranium is strongly, eventually irreversible sorbed on HFO - otherwise, retention by mineral goethite dominates.

Concentration profiles calculated with CASTEM, CHEMTRAP and HYTEC in $1 \mathrm{D}$ and along the 2D symmetry axis are compared and shown by Figure 3. The agreement between codes is satisfactory despite some small discrepancies in $\mathrm{UO}_{2}$ and $\mathrm{U}(\mathrm{aq})$ concentrations. Not shown here, tracer profiles compare very well. The discrepancy is also reflected by comparing the calculated times needed for total dissolution of $\mathrm{UO}_{2}$. The time depends on whether the simulation has been performed in one- or two dimensions: 270 and 170 y (CASTEM), 280 and 165 y (CHEMTRAP), 290 and 185 y (HYTEC). The important difference between $1 \mathrm{D}$ and $2 \mathrm{D}$ grids is due to the $2 \mathrm{D}$ dispersion of $\mathrm{O}_{2}(\mathrm{aq})$ which more correctly simulates the attack of $\mathrm{UO}_{2}$ both at the front and laterally. This effect also explains the increase of the $\mathrm{O}_{2}(\mathrm{aq})$ concentration along the $2 \mathrm{D}$ symmetry axis. The discretization method partly explains the discrepancies. The mass distribution is correctly localized for MHFE (concentrations defined by elements) but is over-estimated for FE (linear interpolation between nodes). A approximative weighting factor (0.8), estimated from geometrical considerations, was therefore applied to FE simulations. Deviations between CHEMTRAP and HYTEC comes from the use of, respectively, triangular and rectangular FE. Obviously, this type of discrepancy decreases with the grid resolution. A second source of error is the iterative coupling scheme of the model. This source is particularly relevant for the numerically 'stiff' cases (e.g., schoepite precipitation at equilibrium in 1D) which presents the greatest discrepancies in $\mathrm{U}(\mathrm{aq})$ and an erroneous re-precipitation of $\mathrm{UO}_{2}$ down-stream, as computed by CASTEM. The differences between results remains however 
acceptable small and the three codes deal reasonably well with sharp redox fronts, often problematic for reactive transport codes (Bäverman et al., 1999).

\section{Spent fuel leaching}

Thick unsaturated host rock could possibly host an underground repository for nuclear spent fuel provided arid climates (e.g. Yucca Mountain). A possible engineering design would be the disposition of corrosion-resistant waste packages in open air galleries (oxidizing conditions). After a very long period of time, package and cladding failures could occur exposing the spent fuel to natural waters. The dripping flow of such waters would be however very weak. The waste packages are unsaturated too, and therefore homogeneously in contact with atmospheric oxygen. Figure 1 schematically illustrates the geometry, which is reduced to a $1 \mathrm{D}$ column for the current source term modeling. Due to the very weak dripping flow, a constant flux was imposed as boundary condition. Constant concentrations (Dirichlet condition) will indeed over-estimate the flux from the host rock. The hydrogeological and geochemical parameters are given by Table 2, and an average temperature of $70{ }^{\circ} \mathrm{C}$ was assumed.

In the specific context of the present HYTEC calculations, the chemical process is controlled by the combination of permanent oxidative dissolution and precipitation kinetics of uranyl phases. After $5000 \mathrm{y}$, the phase transformation of spent fuel to schoepite is completed throughout the package. Uranophane precipitates at the expense of schoepite with a maximum concentration of $10^{-1}$ mol/l at the package top. Soddyite and Boltwoodite-Na also precipitate for a while, but disappear on the long term. The mineralogical sequence is globally in agreement with the experiments of Wronkiewicz et al. (1996). Note that 
secondary hindrance mechanisms, such as precipitation of schoepite around the fuel pellets or water lack in some parts of the waste, may increase this time significantly. A comparison between the results obtained by HYTEC and PHREEQC is shown by Figure 4. The grid size is of 51 nodes. Not shown here, CHEMTRAP produces results virtually identical to HYTEC, which is expected since the system is dominated by geochemistry and both codes share the same geochemical model CHESS. The mineralogical compositions calculated after 100 y by HYTEC and PHREEQC are in very good agreement. For uranophane, the two profiles close to the left axis correspond to precipitation at equilibrium and the other to kinetic precipitation. Time series of $\mathrm{pH}$ and $\mathrm{U}(\mathrm{aq})$ concentration compare fairly well. At the bottom of the waste packages (source term), the change in $\mathrm{pH}$ is small $(\leq 0.5)$ and the $\mathrm{U}(\mathrm{aq})$ concentration

progressively decreases to become constant $\left(10^{-5} \mathrm{~mol} / \mathrm{l}\right)$ after consumption of all $\mathrm{UO}_{2}$. Due to the weak water flux, the $\mathrm{U}$ source term would be constantly tiny.

\section{Conclusions}

Reactive transport models offer the mean of studying geochemically complex systems in a hydrodynamic context. As permanent progress is achieved with regard to both conceptual and mathematical aspects of the model, a verification protocol and standard test-cases are needed in addition to analytical solutions. Benchmarking between peer codes also allows to verify the code behaviour. In this context, calculations of $\mathrm{UO}_{2}$ dissolution and uranium migration has been performed with CASTEM, CHEMTRAP, HYTEC and PHREEQC. The numerical results are in fairly good agreement, although the 
discretization approach and coupling algorithm lead to systematic discrepancies. In complement, 1D simulations which are still commonly performed due to CPU limitations are often unable to correctly model the systems and a $2 \mathrm{D}$ geometry becomes essential. For the proposed applications, it has been shown that the geochemical reactions are closely related to the hydrodynamic processes, especially when the reactions are kinetically controlled, colloid migration is active or the contaminant source significantly disturbs the geochemistry of the migration field. Use of reactive transport models is therefore effective to gain a conceptual and quantitative understanding of such natural and multibarrier systems.

\section{References}

Bruno, J., Casas, I., Cera, E., Ewing, R. C., Werme, L. O., 1995. The assessment of the long-term evolution of the spent nuclear fuel matrix by kinetic, thermodynamic and spectroscopic studies of uranium minerals. Mat. Res. Soc. Symp. Proc. 353, 633-639.

Bäverman, C., Strömberg, B., Moreno, L., Neretnieks, I., 1999. CHEMFRONTS: a coupled geochemical and transport simulation tool. J. Cont. Hydr. 36, 333-351.

Cachoir, C., Guittet, M. J., Gallien, J. P., Trocellier, P., 1996. Uranium dioxide leaching mechanism in a synthetic groundwater in oxic conditions in function of S/V ratio at 96 C. Radiochim. Acta 74, 59-63.

CEA, 1999. Castem2000 user's manual. Tech. rep., CEA (France).

Chavant, G., Roberts, J. G., 1991. An unified physical presentation of mixed, mixed-hybrid finite elements and standard finite difference approximations for the determination of velocities in waterflow problems. Adv. Water Res. 
14-6, 329-348.

CRWMS-MO, 1998. Total System Performance Assessment - Viability Assessment Analyses - Chapter 6 'Waste form degradation, radionuclide mobilization and transport through the engineered barrier system'. Tech. Rep. B-01717-4301-00006 Rev 01, Las Vegas (USA).

Elless, M. P., Lee, S. Y., 1998. Uranium solubility of carbonate-rich uraniumcontaminated soils. Water Air Soil Poll. 107, 147-162.

Gabriel, U., Gaudet, J. P., Spadini, L., Charlet, L., 1998. Reactive transport of uranyl in a goethite column: an experimental and modelling study. Chem. Geol. 151, 107-128.

Gray, W. J., Leider, H. R., Steward, S. A., 1992. Parametric study of LWR spent fuel dissolution kinetics. J. Nucl. Mat. 190, 46-52.

Lucille, P. L., Burnol, A., Ollar, P., 2000. Chemtrap : a hydrogeochemical model for reactive transport in porous media. Hydrol. Proc. 14, 2261-2277.

Nguyen, S. N., Silva, R. J., Weed, H. C., Andrews, J. E., 1992. Standard Gibbs free energies of formation at temperature $303.15 \mathrm{~K}$ of four uranyl silicates: soddyite, uranophane, sodium boltwoodite and sodium weeksite. J. Chem. Thermod. 24, 359-376.

Parkhurst, D. L., Appelo, C. A. J., 1999. User's guide to PHREEQC (Version 2) - a computer program for speciation, batch-reaction, onedimensional transport, and inverse geochemical calculations. Tech. Rep. Water-Resources Investigations 99-4259, USGS (USA).

Pérez, I., Casas, I., Torrero, M. E., Cera, E., Duro, L., Bruno, J., 1997. Dissolution studies of soddyite as a long-term analogue of the oxidative alteration of the spent nuclear fuel matrix. Mat. Res. Soc. Symp. Proc. 465, 565-572.

Serrano, J. A., Rondinella, V. V., Glatz, J. P., Toscano, E. H., Quinones, J., Diaz-Arocas, P. P., Garcia-Serranno, J., 1998. Comparison of the leaching 
behaviour of irradiated fuel, SIMFUEL, and non-irradiated $\mathrm{UO}_{2}$ under oxic conditions. Radiochim. Acta 82, 33-37.

van der Lee, J., 1998. Thermodynamic and mathematical concepts of CHESS. Tech. Rep. LHM/RD/98/39, ENSMP (France).

van der Lee, J., De Windt, L., 2001. Present state and future directions of modeling geochemistry in hydrogeological systems. J. Cont. Hydr. 47, 265282.

van der Lee, J., Ledoux, E., de Marsily, G., 1992. Modeling of colloidal uranium transport in a fractured medium. Journal of Hydrology 139, 135-158.

Wolery, T., 1992. EQ3/6. A software package for geochemical modelling of aqueous systems: package overview and installation guide (version 7.0). Tech. Rep. UCRL-MA-110662 PT I ed., Lawrence Livermore National Laboratory, USA.

Wronkiewicz, D. J., Bates, J. K., Wolf, S. F., Buck, E. C., 1996. Ten-year results from unsaturated drip tests with $\mathrm{UO}_{2}$ at $90 \mathrm{C}$ : implications for the corrosion of spent nuclear fuel. J. Nucl. Mat. 238, 78-95.

Yeh, G., Tripathi, V., 1989. A critical evaluation of recent developments in hydrogeochemical transport models of reactive multichemical components. Water Res. Res. 25(1), 93-108. 



Fig. 1. Lay-out of the benchmarks. 

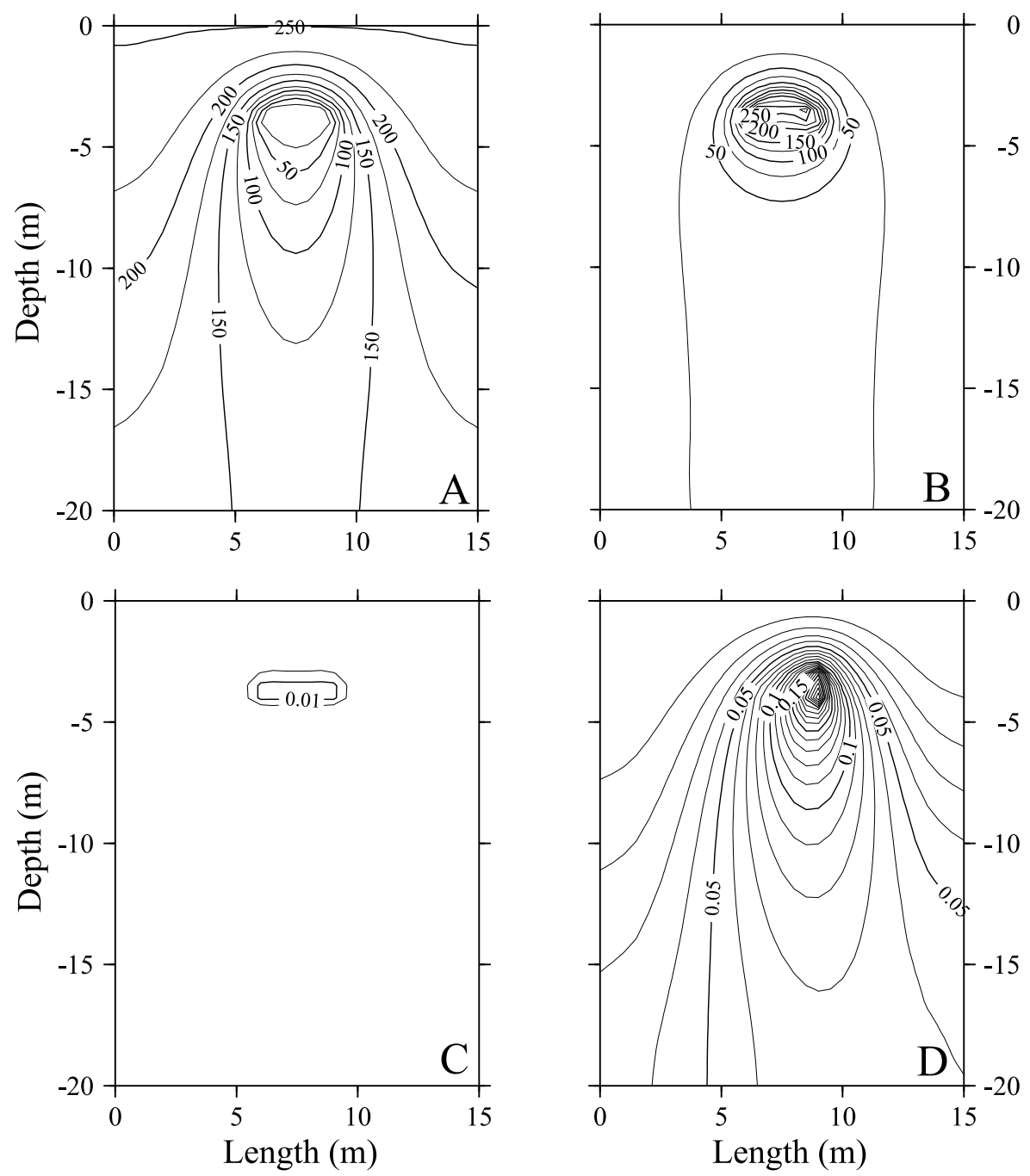

Fig. 2. Concentration profiles ( $\mu \mathrm{mol} / \mathrm{l})$ calculated with HYTEC after $100 \mathrm{y}:(\mathrm{A})$ dissolved oxygen, (B) mobile uranium controlled by schoepite kinetic precipitation, (C) mobile uranium controlled by uranophane precipitation and sorption on goethite, (D) same as C and asymmetric colloidal transport by Hydrous Ferric Oxides. 

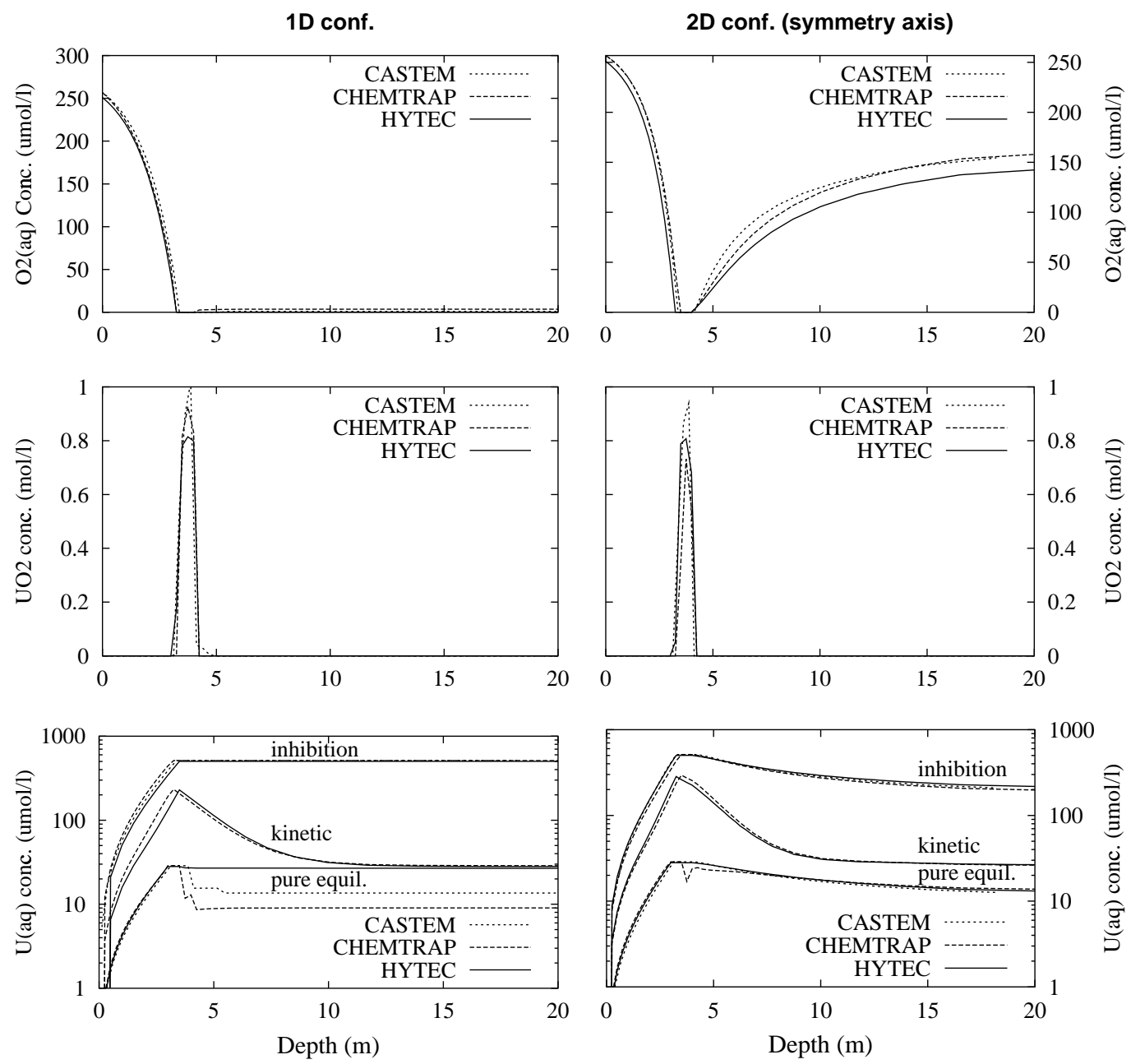

Fig. 3. Calculated concentration profiles of dissolved oxygen, uraninite and dissolved uranium after $100 \mathrm{y}$ in $1 \mathrm{D}$ (left) and 2D (right) configurations. Precipitation of schoepite is either at equilibrium, kinetic or prevented (inhibition). 

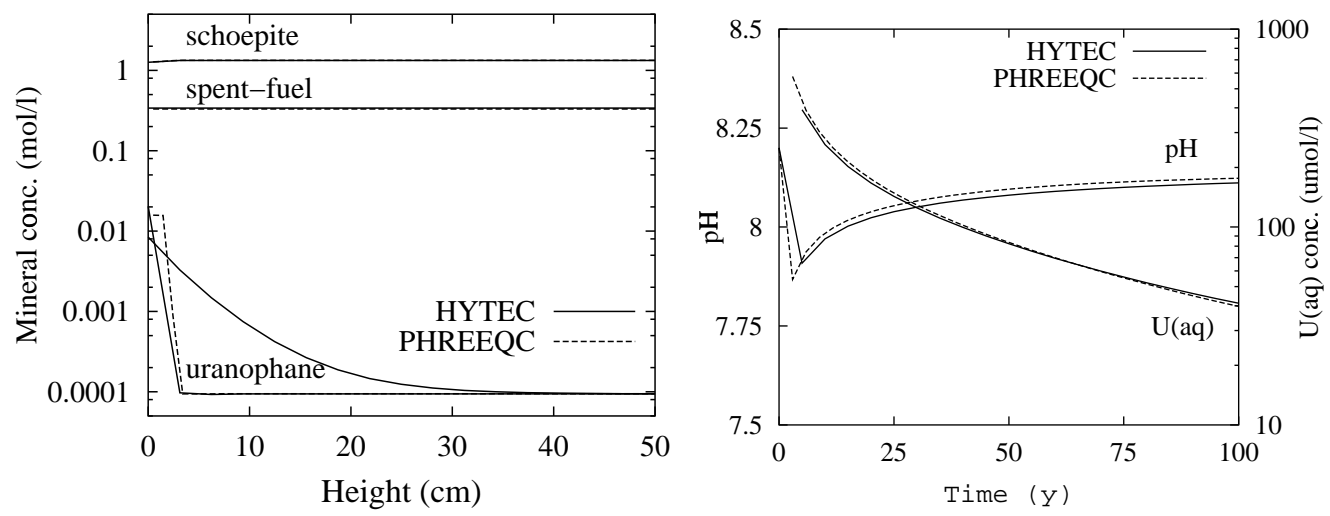

Fig. 4. Evolution of the mineralogical composition over the whole package after $100 \mathrm{y}$, and time profiles of $\mathrm{pH}$ and dissolved uranium concentration at the bottom. Height stands for a vertical section through the package. 


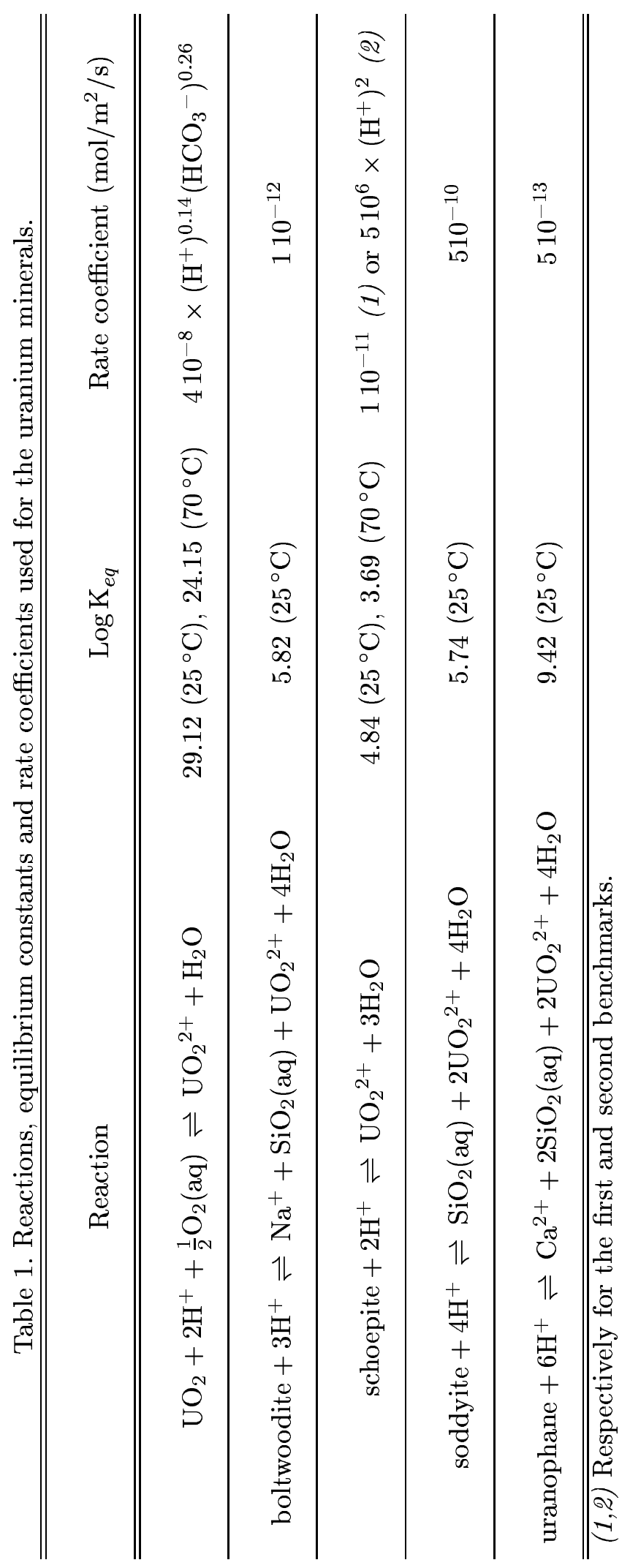


Table 2

Hydrogeological and geochemical parameters of the second benchmark.

\begin{tabular}{|c|c|}
\hline \multirow[t]{2}{*}{ Hydrogeology } & pore velocity $=3.36 \mathrm{~cm} / \mathrm{y}$ \\
\hline & dispersion/diffusion coeff. $=110^{-9} \mathrm{~m}^{2} / \mathrm{s}$ \\
\hline Dripping & $\mathrm{pH}=8.2$, \\
\hline \multirow[t]{2}{*}{ solution } & {$\left[\mathrm{Na}^{+}\right]_{T}=1.99 \mathrm{mmol} / 1,\left[\mathrm{Ca}^{2+}\right]_{T}=0.094 \mathrm{mmol} / 1$} \\
\hline & {$\left[\mathrm{SiO}_{2}\right]_{T}=1.36 \mathrm{mmol} / 1,\left[\mathrm{Cl}^{-}\right]_{T}=0.94 \mathrm{mmol} / 1$} \\
\hline Gases & fug. $C O_{2}=0.001$, fug. $O_{2}=0.20$ \\
\hline \multirow[t]{2}{*}{ Spent fuel } & content $=450 \mathrm{~g} / \mathrm{l}$ of water, \\
\hline & specific surf. $=39 \mathrm{~cm}^{2} / \mathrm{g}$ \\
\hline \multirow[t]{2}{*}{ Secondary minerals } & nucleation surf. $=100 \mathrm{~cm}^{2} / 1$ \\
\hline & specific surf. $=6 \mathrm{~cm}^{2} / \mathrm{g}$ \\
\hline
\end{tabular}

